\title{
MITTEILUNGEN
}

\section{Neue Zeitschriften}

Gegen Ende des Jahres 1952 wurde das 1. Heft der zwanglos erscheinenden Schriftenreihe ,,Die Küste, Archiv für Forschung und Technik an der Nord- und Ostsee" ausgegeben, die u.a. bestimmt ist, die Aufgaben der von 1938-1943 veröffentlichten Zeitschrift ,,Westküste, Archiv für Forschung, Technik und Verwaltung in Marsch und Wattenmeer" fortzuführen. ,Die Küste" wird herausgegeben vom Küstenausschuß Nord- und Ostsee (Vorsitzender: Professor Dr.-Ing. E.h., Dr.-Ing. Agatz, Leiter des Arbeitsausschusses: Ministerialrat Gaye) unter der Schriftleitung von Dr. habil. E. Wohlenberg, Leiter der Forschungsstelle Westküste, Husum, Nissenhaus. Das mit Geleitworten des Bundesverkehrsministers und der niedersächsischen und schleswig-holsteinischen Minister für Ernährung, Landwirtschaft und Forsten versehene erste Heft ist der deutschen Norseeküste gewidmet. Den Abbruchserscheinungen am West- und Nordrand von Norderney gelten zwei Beiträge: R. Thilo und G. Kurzak erörtern in einem Auszug aus dem Bericht des Wasser- und Schiffahrtsamtes Norden, Forschungsstelle Norderney, die Ursachen der Abbruchserscheinungen, und der Küstenausschuß Nord- und Ostsee, Arbeitsgruppe Norderney, nimmt zu diesen Untersuchungen und den vorgeschlagenen Schutzmaßnahmen gutachtlich Stellung. Ähnliche Ausblicke, wie sie in den vorgenannten. Beiträgen für Norderney behandelt werden, eröffnet für eine spätere Zukunft W. Ni ebuhr für Borkum in seinem Überblick über die neuere Entwicklung der Außenems, und K. Lüders beleuchtet ein entsprechendes Problem für die Insel Wangerooge in dem Aufsatz ,,Die Wirkung der Buhne $\mathrm{H}$ in Wangerooge-West auf das Seegat Harle" , mit der abschließenden Feststellung, daß die Verlängerung dieser Buhne die Wirkung gehabt hat, Westwangerooge wieder einen hochwasserfreien Strand zu verschaffen. Die zweite Hälfte des Heftes füllt eine umfangreiche nachgelassene Studie von H. Schelling über die Sturmfluten an der Westküste von Schleswig-Holstein, die durch die im Anschluß an die Sturmflut vom 9. und 10. Februar 1949 wieder aufgeworfene Frage veranlaßt worden ist, ob die Deiche Schleswig-Holsteins genügend hoch sind. Eine abschließende Antwort auf diese Frage wird nicht gegeben ${ }^{1}$. - Das zweite Heft der „Küste" soll den Abbruchserscheinungen am Brodtener Ufer bei Travemünde gewidmet sein.

Mit Beginn des Jahres 1953 wird das 1. Heft von Band 14 der Zeitschrift ,Der Seewart" erscheinen. Diese, ,Nautische Zeitschrift für die deutsche Seeschiffahrt" wird auf Wunsch nautischer Kreise jetzt vom Deutschen Hydrographischen Institut und vom Deutschen Wetterdienst, Seewetteramt, Hamburg, herausgegeben; in die Schriftleitung teilen sich Nautiker und Wissenschaftler der beiden Institute und der Seefahrtschulen in Hamburg-Altona und Bremen. Wie der langjährige Schriftleiter des von der Deutschen Seewarte begründeten ,,Seewart", E. Römer, in einem Geleitwort betont, soll auch die neueröffnete Zeitschrift wieder dem Gedankenaustausch zwischen dem in der Praxis stehenden Nautiker und den für die Seefahrt arbeitenden Instituten dienen. Der einleitende Aufsatz von M. Rodewald zeigt an Hand des meteorologischen Tagebuchs des Dampfers ,Holstein“", daß bei der Überquerung des Nordatlantischen Ozeans von Westen nach Osten das Mitlaufen mit einem Tief nicht immer angenehmer ist als das Gegenandampfen auf Ost-West-Kurs, wie aber bei Überholung eines Sturmtiefs durch eine schnellere Zyklone die Wetterlage sich infolge Interferenz beider Störungen vorübergehend beruhigt. L. Schnegelsberg bespricht, Falsche Radarechos $^{\text {", }}$, und F. Meincke schildert die Ausreise des, Pamir" in der Nordsee und der Biskaya vom meteorologischen Standpunkt. O. Hebecker stellt Seegangsbetrachtungen zum Verlust des ,Thor" und der ,Irene Oldendorff" an. H. Burmester und W. Platzoeder befassen sich mit Fragen der Betonnung, und F. Nusser erläutert (am Beispiel der deutschen Seekarte ,Europäisches Nordmeer und Barents-See, Mittel und Ostblatt") seine Grundsätze und Methoden der Eisgrenzendarstellung. Beiträge zur Hafen- und Küstenkunde und eine Rubrik ,Seemännisches" runden den Inhalt des 40 Seiten starken Heftes ab.

1 Vgl. hierzu die Schlußbemerkung von G. Tomezak in seiner Untersuchung ,Die Sturmfluten vom 9. und 10. Februar an der deutschen Nordseeküste"6, Dtsch. Hydrogr. Z. 3 (1950), $227-240$. 